\title{
PROCESS CAPABILITY ANALYSIS PADA NUT (STUDI KASUS: PT SANKEI DHARMA INDONESIA)
}

\author{
Helena Sisilia R. S.*, Hendy Tannady* \\ Program Studi Teknik Industri, Universitas Bunda Mulia \\ Jl. Lodan Raya No. 2, Ancol-Jakarta Utara
}

(Received: December 28, 2016/ Accepted: July 17, 2017)

\begin{abstract}
Abstrak
PT Sankei Dharma Indonesia merupakan perusahaan yang bergerak di bidang otomotif. Salah satu produk yang dihasilkan adalah nut (berfungsi sebagai dudukan kabel sensor). Proses nut dianggap critical to quality, dimana hasil dari proses memperhatikan inside diameter nut yang dihasilkan PT A, PT B, dan PT C. Peningkatan kinerja proses dilakukan dengan menggunakan process capability yang merupakan salah metode dari Statistical Process Control. Hasil dari penelitian menunjukkan bahwa process capability pada inside diameter PT B berjalan dengan tidak sesuai, di mana nilai capability index $C p=0.57, C p l=0.58, C p u=0.56, C p k=0.56$, dan $C p m=0.54$. Sedangkan process capability pada inside diameter PT A dan PT C tergolong sangat memuaskan. Di mana nilai capability index PT $C C p=2.34, C p l=2.37, C p u=2.30, C p k=2.30$, dan $C p m=2.26$. Dan nilai capability index $P T A$ $C p=1.77, C p l=1.79$, Cpu $=1.75, C p k=1.75$, dan $C p m=1.86$.
\end{abstract}

Kata Kunci: Proses Kontrol Statistik, Indeks Kapasitas Proses, Distribusi Normal.

\begin{abstract}
PT Sankei Dharma Indonesia is a company engaged in the automotive field. One of the resulting product is a nut (functioning as a sensor cable holder). Nut process is considered critical to quality, which result from the attention generated inside diameter nut PT A, PT B, dan PT C. Improved performance of process is done by using process capability, which is one method of Statistical Process Control. Results from the study showed that the process capability to the inside diameter of the PT B running is not appropriate, in which the value of capability index $C p=0,57 ; C p l=0,58 ; C p u=0,56$; $C p k=0,56$, dan Cpm =0,54; While the process capability to inside diameter PT A and PT C as very satisfactory. Where the value of capability index $P T C C p=2.34, C p l=2.37, C p u=2.30, C p k=$ 2.30, dan Cpm = 2.26. And the value of capability index $P T A C p=1.77, C p l=1.79, C p u=1.75$, Cpk $=1.75$, dan Cpm $=1.86$.
\end{abstract}

Keywords: Statistical Process Control, Process Capability Index, Normal Distribution.

\section{Pendahuluan}

Perkembangan teknologi yang semakin cepat menyebabkan semakin ketatnya persaingan antar industri di Indonesia, terutama industri otomotif. Agar dapat bertahan dari persaingan tersebut, maka perusahaan berlomba-lomba meningkatkan kualitas untuk dapat memenuhi kebutuhan customer. Salah satu perusahaan yang ikut berupaya meningkatkan kualitasnya ialah PT Sankei Dharma Indonesia. PT Sankei Dharma Indonesia ini merupakan perusahaan joint venture antara Sankei Giken Kogyo, Jepang dan PT Dharma Polimetal yang bergerak di bidang

\footnotetext{
*) Penulis Korespondensi. email: helenaratna22@gmail.com; hendytannady@yaho.com
}

otomotif. Produk utama yang diproduksi adalah exhaust system, body parts exterior untuk mobil, bagian umum dan bagian khusus. Pada penelitian ini, peneliti hanya berfokus pada kualitas produk nut (berfungsi sebagai dudukan kabel sensor).

Dalam memproduksi suatu produk, hal utama yang menjadi fokus dari perusahaan adalah kualitas. Kualitas dapat didefinisikan sebagai kemampuan untuk memenuhi kebutuhan customer. Tidak hanya itu, pengendalian kualitas/quality control (QC) sangat diperlukan untuk dapat mempertahankan dan meningkatkan kualitas dari produk yang dihasilkan. Statistical qualtity control (SQC) merupakan salah satu metode dari QC. SQC yang biasanya digunakan ialah acceptance sampling (AC), control chart, dan process capability analysis ${ }^{3)}$. Umumya, karakteristik mutu dinyatakan dalam bentuk pengukuran numerik 
dan merupakan jenis data variabel, sehingga perlu adanya pengendalian terhadap rata-rata dan variabilitas proses. Pengendalian dari rata-rata proses dapat dilakukan dengan $\bar{x}$-chart dan pemonitoran proses variabilitas dengan menggunakan $s$-chart atau $R$-chart. Dalam penelitian ini, pengendalian dilakukan menggunakan $\bar{x} \& R$-chart. Berikut ini adalah rumus batas kendali untuk $\bar{x} \& R-$ chart.

1.Batas kendali $\bar{x}-$ chart

$$
\begin{aligned}
& U C L=\overline{\bar{x}}+A_{2} \bar{R} \\
& C L=\overline{\bar{x}} \\
& L C L=\overline{\bar{x}}-A_{2} \bar{R}
\end{aligned}
$$

2.Batas kendali $R-\operatorname{chart}$

$$
\begin{aligned}
& U C L=D_{4} \bar{R} \\
& C L=\bar{R} \\
& L C L=D_{3} \bar{R}
\end{aligned}
$$

\section{Process Capability Indices}

Process capability indices merupakan kombinasi dari process parameters dengan spesifikasi produk. Process capability indices digunakan untuk mengukur hubungan kinerja antara proses aktual dengan batas spesifikasi yang diharapkan yang bertujuan untuk meningkatkan kualitas proses dan produktivitas ${ }^{3)}$. Capability indices umumnya menganggap bahwa data berdistribusi normal dan proses terkendali. Selain itu, untuk mendapatkan hasil yang efektif maka target proses dan batas spesifikasi harus ditentukan berdasarkan kebutuhan customer. Dalam penelitian ini, process capability index yang digunakan adalah $\mathrm{C}_{\mathrm{p}}, \mathrm{C}_{\mathrm{pk}}\left(\mathrm{C}_{\mathrm{pu}}\right.$ dan $\left.\mathrm{C}_{\mathrm{pk}}\right), \mathrm{C}_{\mathrm{pm}}, \mathrm{C}_{\mathrm{pmk}}$.

$\mathrm{Cp}$ : proses dasar process capability index dengan mengevaluasi kinerja proses yang terkait dengan batas spesifikasi yang telah ditentukan.

$$
C_{p}=\frac{U S L-L S L}{6 \sigma}
$$

$\mathrm{C}_{\mathrm{pk}}$ : kapabilitas actual $\left(\mathrm{C}_{\mathrm{pk}}\right)$ bertujuan untuk menunjukkan kondisi aktual sistem sebenarnya.

$$
\begin{aligned}
& C_{p k}=\min .\left[C_{p u}, C_{p l}\right], \text { dimana } \\
& C_{p l}=\frac{\bar{x}-L S L}{3 \sigma} \operatorname{dan} C_{p u}=\frac{U S L-\bar{x}}{3 \sigma}
\end{aligned}
$$

$\mathrm{C}_{\mathrm{pm}}: \mathrm{C}_{\mathrm{pm}}$ memperkirakan process capability di sekitar target $\mathrm{T}$ selalu lebih besar dari nol. Proses di sekitar output dianggap normal. Cpm dikenal juga sebagai Taguchi Capability Index ${ }^{4)}$.

$$
C_{p m}=\frac{C_{p}}{\sqrt{1+\left(\frac{\mu-T}{\sigma}\right)^{2}}}
$$

\begin{tabular}{|c|c|}
\hline Capability Index & $\begin{array}{c}\text { Perkiraan kondisi yang } \\
\text { terjadi }\end{array}$ \\
\hline $\mathrm{Cpk}=\mathrm{Cp}$ & $\begin{array}{l}\text { Mean proses tepat berada di } \\
\text { tengah batas spesifikasi }\end{array}$ \\
\hline $\mathrm{Cp}<1$ & Proses berjalan tidak sesuai \\
\hline $1 \leq \mathrm{Cpk}<1.33$ & Proses berjalan sesuai \\
\hline $\mathrm{Cp} \geq 1.33$ & Proses cukup memuaskan \\
\hline $\mathrm{Cp} \geq 1.66$ & Proses sangat memuaskan \\
\hline $\mathrm{Cpk} \neq \mathrm{Cp}$ & $\begin{array}{l}\text { Mean proses tidak tepat berada } \\
\text { di tengah batas spesifikasi }\end{array}$ \\
\hline $\mathrm{Cpk}<0$ & $\begin{array}{l}\text { Mean proses berada di luar } \\
\text { batas spesifikasi }\end{array}$ \\
\hline $\mathrm{Cpk}<-1$ & $\begin{array}{l}\text { Seluruh proses berada di luar } \\
\text { batas spesifikasi }\end{array}$ \\
\hline $\mathrm{Cpk}=0$ & $\begin{array}{l}\text { Setengah proses berada di luar } \\
\text { batas spesifikasi }\end{array}$ \\
\hline
\end{tabular}

$\mathrm{C}_{\mathrm{pmk}}$ : $\mathrm{C}_{\mathrm{pmk}}$ merupakan kombinasi indeks $\mathrm{C}_{\mathrm{pk}}$ dan $\mathrm{C}_{\mathrm{pm}}$. Umumnya yang digunakan ialah $\mathrm{C}_{\mathrm{pk}}$.

$$
\begin{aligned}
& C_{p m k}=\min .\left[C_{d u}, C_{d l}\right], \text { dimana } \\
& C_{d u}=\frac{U S L-\mu}{3 \sqrt{\sigma^{2}+(\mu-\tau)^{2}}} \\
& C_{d l}=\frac{\mu-L S L}{3 \sqrt{\sigma^{2}+(\mu-\tau)^{2}}}
\end{aligned}
$$

1) Tabel berikut ini akan merangkum perbandingan nilai $\mathrm{Cp}$ dan $\mathrm{Cpk}$ beserta estimasi proses yang terjadi.

Tabel 1. Estimasi Proses Sesuai dengan Capability Indices

\section{Metodologi Penelitian}

Sifat penelitian ini adalah sekunder karena menggunakan data history perusahaan yang didapatkan dari salah satu karyawan PT Sankei Dharma Indonesia. Penelitian ini menggunakan data inspeksi inside diameter produk nut. Hasil akhir dari proses ini, yaitu inside diameter produk nut dianggap critical-to-quality. Data yang digunakan terdiri dari 100 sample data yang diperoleh dari observasi terhadap tiga supplier. Pada tahap pengolahan, data dikelompokkan menjadi 20 subgroup dan setiap subgroup terdiri dari 5 observasi. Pengolahan data pada tahap penelitian ini dimulai dengan melakukan uji normalitas data. Setelah data berdistribusi normal, maka tahap selanjutnya adalah tahap pemonitoran dengan menggunakan $\bar{x}-R$ Charts. 2) Jika terdapat data yang berada di luar batas kendali (outlier), maka data tersebut dipertahankan. Hal ini disebabkan karena keterbatasan peneliti untuk mencari assignable causes dari proses tersebut dan ketentuan jumlah data yang digunakan dalam proses pemonitoran dan penghitungan. Tahap terakhir dan menjadi tujuan dari penelitian ini adalah menghitung process capability index dari inside diameter produk nut dari ketiga supplier, yaitu PT A, PT B, dan PT C.

\section{Analisis dan Pembahasan Data}

Bentuk akhir produk yang dihasikan dari proses produksi adalah converter. Nut merupakan suatu komponen yang terdapat di dalam converter dan berfungsi sebagai dudukan untuk kabel sensor. Proses pembuatan nut merupakan proses yang dianggap critical to quality. Proses pembuatan nut dapat dilihat pada gambar 1 . berikut ini. 


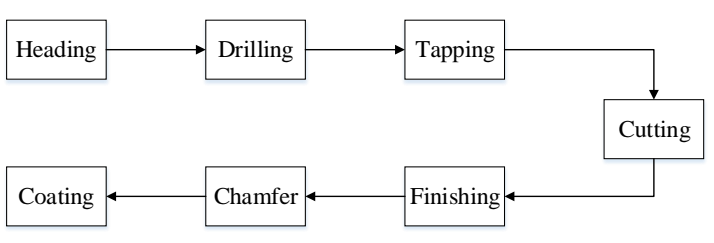

Gambar 1. Proses Pembuatan Nut

Berikut ini adalah data inspeksi inside diameter nut pada PT A, PT B, dan PT C.

Tabel 2. Data Inspeksi Nut

\begin{tabular}{|c|c|c|c|}
\hline Sample & $\begin{array}{c}\text { Inside } \\
\text { Diameter } \\
\text { PT. A } \\
\text { (mm) }\end{array}$ & $\begin{array}{c}\text { Inside } \\
\text { Diameter } \\
\text { PT. B } \\
\text { (mm) }\end{array}$ & $\begin{array}{c}\text { Inside } \\
\text { Diameter } \\
\text { PT. C } \\
\text { (mm) }\end{array}$ \\
\hline 1 & 16.65 & 16.662 & 16.642 \\
\hline 2 & 16.658 & 16.63 & 16.652 \\
\hline 3 & 16.657 & 16.682 & 16.644 \\
\hline 4 & 16.66 & 16.661 & 16.646 \\
\hline 5 & 16.658 & 16.666 & 16.651 \\
\hline 6 & 16.655 & 16.646 & 16.661 \\
\hline 7 & 16.654 & 16.675 & 16.645 \\
\hline 8 & 16.669 & 16.582 & 16.652 \\
\hline 9 & 16.651 & 16.672 & 16.65 \\
\hline 10 & 16.629 & 16.652 & 16.65 \\
\hline 11 & 16.658 & 16.677 & 16.641 \\
\hline 12 & 16.643 & 16.655 & 16.654 \\
\hline 13 & 16.649 & 16.627 & 16.651 \\
\hline 14 & 16.638 & 16.647 & 16.658 \\
\hline 15 & 16.651 & 16.63 & 16.645 \\
\hline 16 & 16.66 & 16.627 & 16.643 \\
\hline 17 & 16.653 & 16.633 & 16.655 \\
\hline 18 & 16.646 & 16.633 & 16.662 \\
\hline 19 & 16.658 & 16.632 & 16.65 \\
\hline 20 & 16.635 & 16.655 & 16.647 \\
\hline 21 & 16.656 & 16.641 & 16.65 \\
\hline 22 & 16.643 & 16.639 & 16.649 \\
\hline 23 & 16.657 & 16.696 & 16.652 \\
\hline 24 & 16.652 & 16.703 & 16.643 \\
\hline 25 & 16.653 & 16.594 & 16.65 \\
\hline 26 & 16.652 & 16.655 & 16.658 \\
\hline 27 & 16.659 & 16.665 & 16.656 \\
\hline 28 & 16.653 & 16.676 & 16.651 \\
\hline 29 & 16.641 & 16.648 & 16.642 \\
\hline 30 & 16.64 & 16.665 & 16.651 \\
\hline
\end{tabular}

\begin{tabular}{|c|c|c|c|}
\hline 31 & 16.634 & 16.635 & 16.659 \\
\hline 32 & 16.64 & 16.673 & 16.641 \\
\hline 33 & 16.665 & 16.689 & 16.646 \\
\hline 34 & 16.638 & 16.673 & 16.665 \\
\hline 35 & 16.662 & 16.698 & 16.642 \\
\hline 36 & 16.652 & 16.691 & 16.642 \\
\hline 37 & 16.643 & 16.642 & 16.649 \\
\hline 38 & 16.653 & 16.68 & 16.67 \\
\hline 39 & 16.646 & 16.666 & 16.655 \\
\hline 40 & 16.644 & 16.616 & 16.665 \\
\hline 41 & 16.663 & 16.738 & 16.652 \\
\hline 42 & 16.646 & 16.622 & 16.657 \\
\hline 43 & 16.646 & 16.7 & 16.659 \\
\hline 44 & 16.656 & 16.649 & 16.646 \\
\hline 45 & 16.671 & 16.628 & 16.636 \\
\hline 46 & 16.641 & 16.689 & 16.638 \\
\hline 47 & 16.642 & 16.686 & 16.64 \\
\hline 48 & 16.638 & 16.634 & 16.664 \\
\hline 49 & 16.638 & 16.655 & 16.657 \\
\hline 50 & 16.658 & 16.644 & 16.655 \\
\hline 51 & 16.651 & 16.611 & 16.656 \\
\hline 52 & 16.642 & 16.688 & 16.646 \\
\hline 53 & 16.647 & 16.684 & 16.646 \\
\hline 54 & 16.645 & 16.629 & 16.651 \\
\hline 55 & 16.657 & 16.683 & 16.642 \\
\hline 56 & 16.666 & 16.664 & 16.652 \\
\hline 57 & 16.651 & 16.655 & 16.654 \\
\hline 58 & 16.647 & 16.62 & 16.652 \\
\hline 59 & 16.665 & 16.638 & 16.652 \\
\hline 60 & 16.643 & 16.61 & 16.649 \\
\hline 61 & 16.656 & 16.602 & 16.655 \\
\hline 62 & 16.651 & 16.621 & 16.662 \\
\hline 63 & 16.652 & 16.723 & 16.662 \\
\hline 64 & 16.661 & 16.614 & 16.651 \\
\hline 65 & 16.658 & 16.627 & 16.656 \\
\hline 66 & 16.648 & 16.628 & 16.646 \\
\hline 67 & 16.656 & 16.598 & 16.631 \\
\hline 68 & 16.65 & 16.647 & 16.652 \\
\hline 69 & 16.643 & 16.688 & 16.639 \\
\hline 70 & 16.656 & 16.608 & 16.657 \\
\hline 71 & 16.644 & 16.614 & 16.646 \\
\hline 72 & 16.671 & 16.667 & 16.646 \\
\hline 73 & 16.653 & 16.664 & 16.661 \\
\hline 74 & 16.641 & 16.676 & 16.655 \\
\hline
\end{tabular}




\begin{tabular}{cccc}
\hline 75 & 16.662 & 16.699 & 16.651 \\
76 & 16.658 & 16.671 & 16.653 \\
77 & 16.651 & 16.623 & 16.641 \\
78 & 16.654 & 16.648 & 16.657 \\
79 & 16.641 & 16.667 & 16.651 \\
80 & 16.646 & 16.721 & 16.655 \\
81 & 16.634 & 16.643 & 16.656 \\
82 & 16.651 & 16.632 & 16.636 \\
83 & 16.655 & 16.645 & 16.653 \\
84 & 16.634 & 16.641 & 16.66 \\
85 & 16.645 & 16.636 & 16.641 \\
86 & 16.651 & 16.635 & 16.645 \\
87 & 16.658 & 16.679 & 16.654 \\
88 & 16.642 & 16.625 & 16.652 \\
89 & 16.643 & 16.604 & 16.652 \\
90 & 16.641 & 16.669 & 16.655 \\
91 & 16.654 & 16.659 & 16.649 \\
92 & 16.652 & 16.61 & 16.646 \\
93 & 16.654 & 16.656 & 16.666 \\
94 & 16.659 & 16.637 & 16.648 \\
95 & 16.644 & 16.676 & 16.653 \\
96 & 16.656 & 16.678 & 16.658 \\
97 & 16.637 & 16.626 & 16.647 \\
98 & 16.67 & 16.615 & 16.647 \\
99 & 16.647 & 16.625 & 16.638 \\
100 & 16.645 & 16.592 & 16.649 \\
\hline & & & \\
\hline
\end{tabular}

\section{Uji Normalitas}

Pengolahan probability plot untuk inside diameter menggunakan software MINITAB 16. Hasil probability plot untuk inside diameter PT A diperoleh nilai P-value sebesar 0.284.

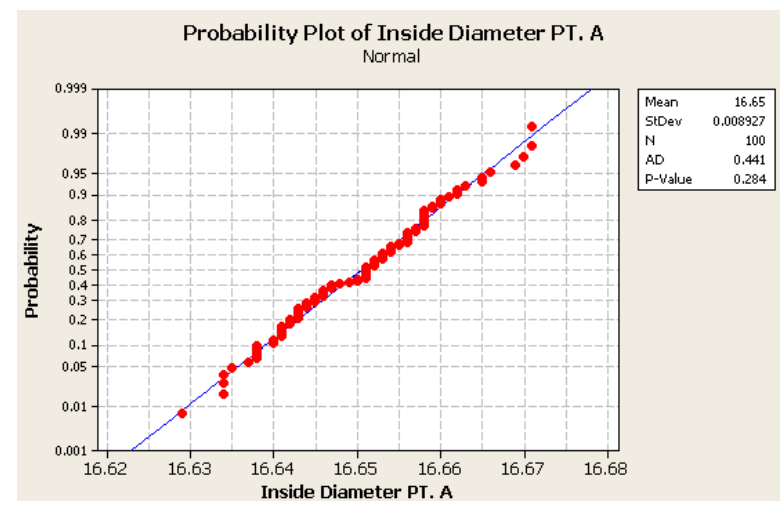

Gambar 2. Probability Plot Inside Diameter PT A

Dari hasil pengolahan data menggunakanprobability plot untuk inside diameter
PT B menunjukkan diperoleh nilai P-value sebesar 0.536 .

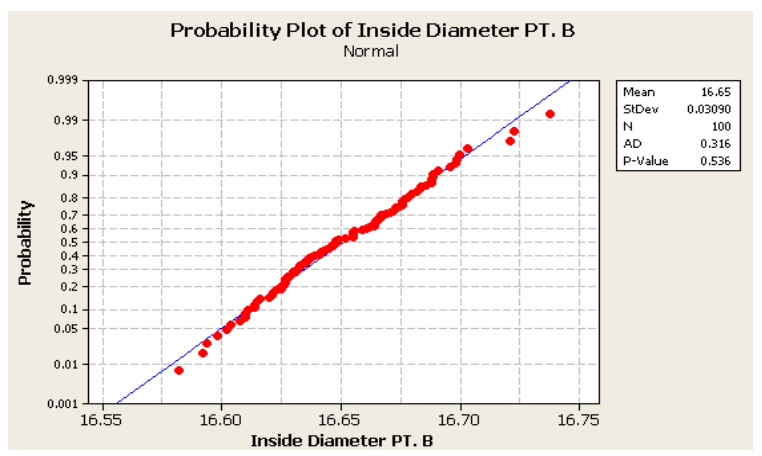

Gambar 3. Probability Plot Inside Diameter PT B

Dari hasil pengolahan data menggunakan probability plot untuk inside diameter PT B diperoleh nilai P-value sebesar 0.590.

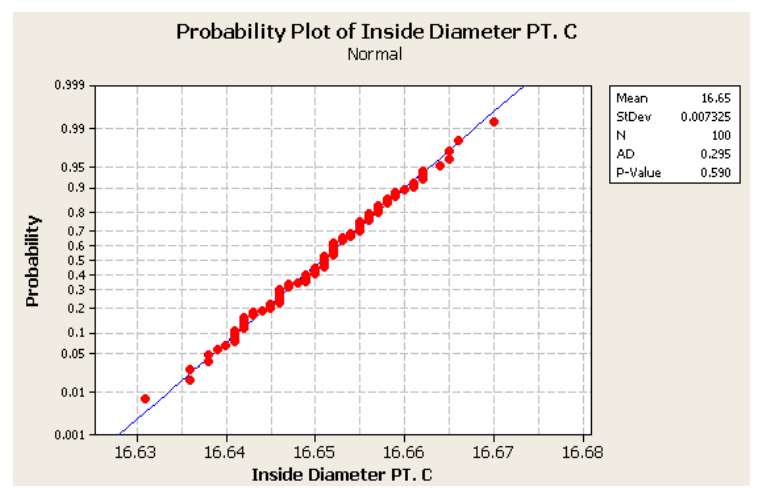

Gambar 4. Probability Plot Inside Diameter PT C

Ketiga grafik data inside diamater di atas menunjukkan bahwa data tersebar di tengah - tengah garis dan terdapat sedikit data yang berada di luar garis tengah sehingga dapat diindikasikan data tersebut berdistribusi normal. Selain itu, pernyataan tersebut diperkuat dengan nilai $\mathrm{P}$-value yang besar dari $\alpha(\alpha=0.01)$ yang dapat diartikan bahwa $\mathrm{H}_{0}$ diterima dan data tersebut berdistribusi normal.

\section{Pemonitoran Cotrol Chart}

Pengolahan control charts untuk inside diameter menggunakan software MINITAB 16. Setiap produk mempunyai batas spesifikasi yang berarti toleransi yang diizinkan agar produk itu berada dalam kategori. Inside diameter dari produk nut ini memiliki USL $16.6 \mathrm{~mm}$ dan LSL $16.7 \mathrm{~mm}$. Data yang dikelompokkan menjadi 20 subgroup, di mana setiap subgroup terdiri dari 5 observasi.

Pada grafik $\bar{x}$ - charts inside diameter PT A menunjukkan bahwa pada kondisi ini $\bar{x}=16.65052, \quad \mathrm{UCL}=16.66267$, dan $\mathrm{LCL}=$ 16.63687. Sedangkan pada grafik R-charts menunjukkan bahwa data mempunyai range $(\mathrm{R})=$ $0.202107, \mathrm{UCL}=0.04455$, dan $\mathrm{LCL}=0$. 


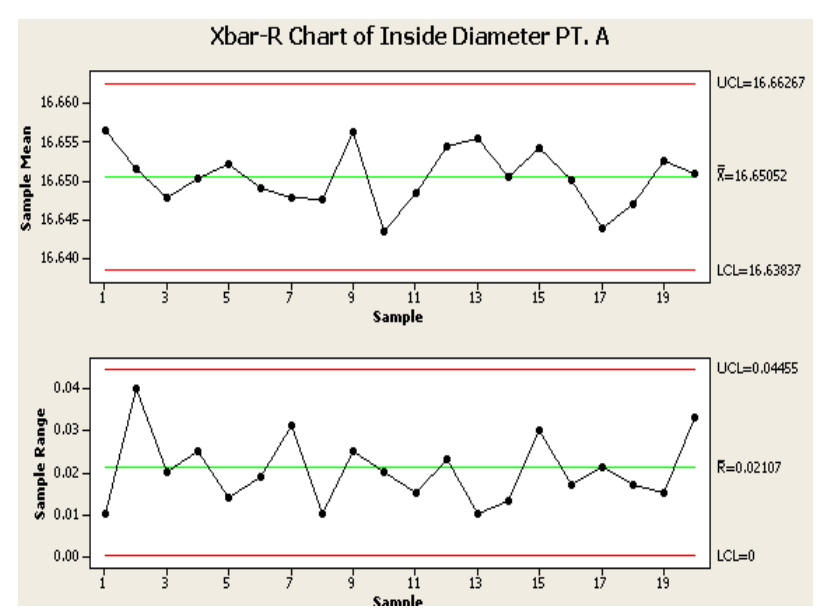

Gambar 5. $\bar{x}-R$ Charts Inside Diameter PT A

Pada grafik $\bar{x}$ - charts inside diameter PT B menunjukkan bahwa pada kondisi ini $\bar{x}=16.65105$, UCL $=16.69301$, dan LCL $=$ 16.60909. Sedangkan pada grafik R-charts menunjukkan bahwa data mempunyai range $(\mathrm{R})=$ $0.0727, \mathrm{UCL}=0.1538$, dan $\mathrm{LCL}=0$.

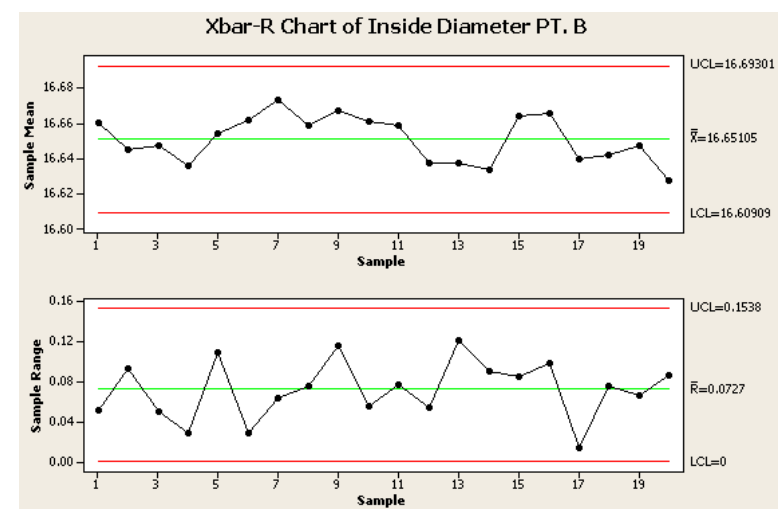

Gambar 6. $\bar{x}-R$ Charts Inside Diameter PT B

Pada grafik $\bar{x}$ - charts inside diameter PT C menunjukkan bahwa pada kondisi ini $\bar{x}=16.65071$, UCL $=16.66088$, dan $\mathrm{LCL}=$ 16.64054. Sedangkan pada grafik R-charts menunjukkan bahwa data mempunyai range $(\mathrm{R})=$ $0.01763, \mathrm{UCL}=0.03727$, dan $\mathrm{LCL}=0$.

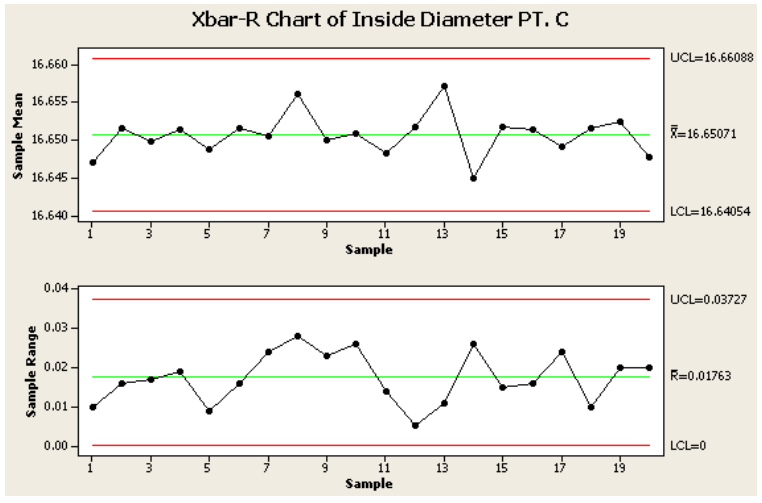

Gambar 7. $\bar{x}-R$ Charts inside diameter PT C

Dari ketiga grafik $\bar{x}-R$ Charts di atas, menunjukkan bahwa semua data berada di dalam batas kendali.

\section{Capability Process}

Pada gambar 8. Process Capability of Inside Diameter PT A dapat dilihat bahwa bentuk histogram pada proses ini ramping, yang dapat diartikan bahwa proses ini memiliki sedikit variasi dan proses yang dihasilkan sangat memuaskan. Hal tersebut ditunjukkan dari nilai $\mathrm{Cp}$ yang dimiliki lebih besar dari 1.66 .

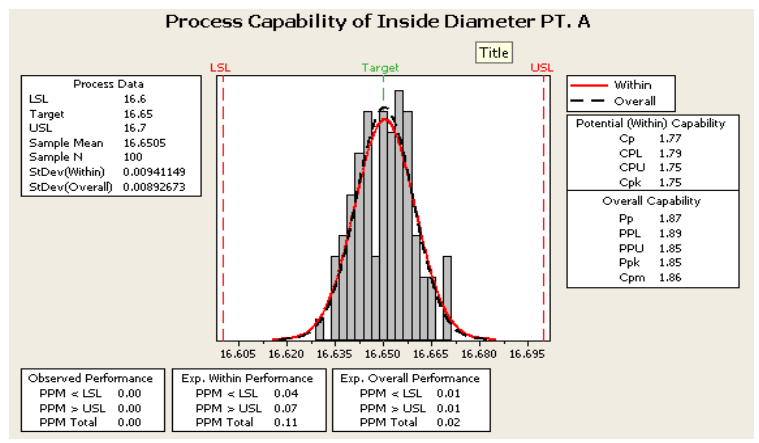

Gambar 8. Process Capability of Inside Diameter PT A

Pada gambar 9. Process Capability of Inside Diameter PT B dapat dilihat bahwa bentuk histogram pada proses ini sangat lebar, yang dapat diartikan bahwa proses ini memiliki banyak variasi dan proses yang dihasilkan berjalan dengan tidak sesuai. Hal tersebut ditunjukkan dari nilai $\mathrm{Cp}$ yang dimiliki lebih kecil dari 1. 


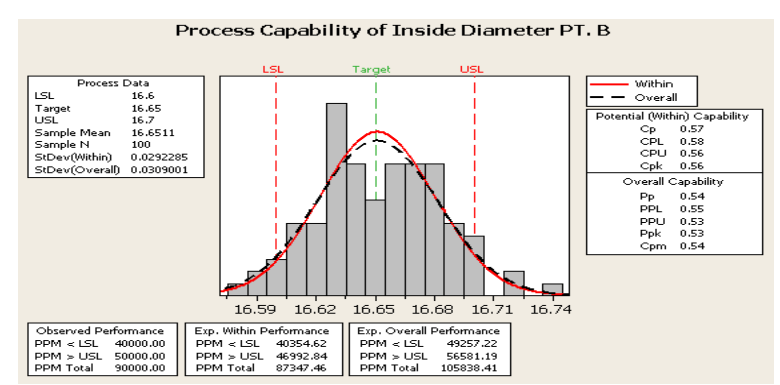

Gambar 9. Process Capability of Inside Diameter PT B

Pada gambar 10. Process Capability of Inside Diameter PT C dapat dilihat bahwa bentuk histogram pada proses ini ramping, yang dapat diartikan bahwa proses ini memiliki sedikit variasi dan proses yang dihasilkan sangat memuaskan. Hal tersebut ditunjukkan dari nilai $\mathrm{Cp}$ yang dimiliki lebih besar dari 1.66.

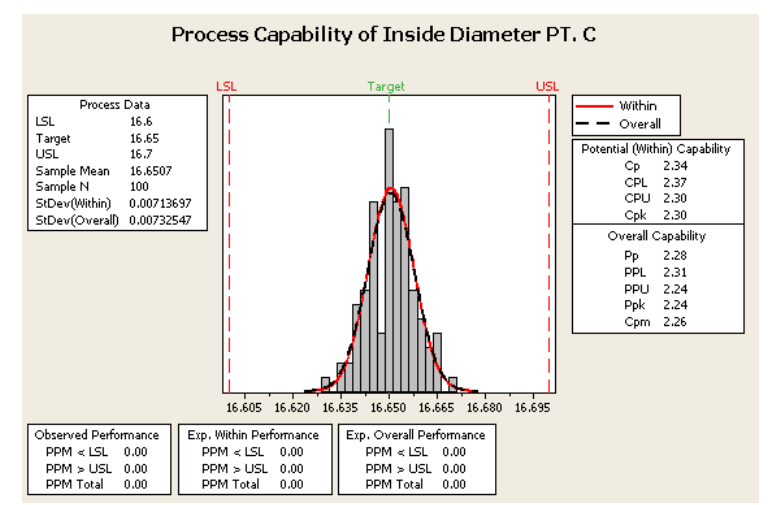

Gambar 10. Process Capability of Inside Diameter PT C

Ketiga process capability of inside diameter menunjukkan bentuk grafik yang berbeda-beda. Hal itu disebabkan oleh variasi yang muncul. Dari ketiga proses tersebut, inside diameter PT C mempunyai proses yang sangat memuaskan hal tersebut dapat dilihat dari nilai $\mathrm{Cp}$ yang dimiliki lebih besar dibandingkan dengan proses lainnya.

\section{Kesimpulan}

Berdasarkan dari hasil analisis dan pembahasan yang dilakukan, maka dapat disimpulkan nilai capability index $\mathrm{Cp}, \mathrm{Cpl}, \mathrm{Cpu}, \mathrm{Cpk}$, dan $\mathrm{Cpm}$ dari proses inside diameter nut PT A adalah 1.77; 1.79; $1.75 ; 1.75 ; 1.86$, inside diameter nut PT $\mathrm{B}$ adalah 0.57; 0.58; 0.56; 0.56; 0.54, dan inside diameter nut PT C adalah 2.34; 2.37; 2.30; 2.30; dan 2.26. Hasil tersebut menunjukkan bahwa proses inside diameter nut PT C sangat memuaskan, sedangkan proses inside diameter nut PT B berjalan dengan tidak sesuai dengan yang diinginkan. Hal tersebut disebabkan oleh banyaknya variasi pada produk yang dihasilkan. Sehingga perusahaan perlu menindaklanjuti ketidakandalan proses yang terjadi.

Daftar Pustaka

Maimury, Yona \& Tannady, Hendy. 2015. “Analisis Kinerja Proses Latex Dipping Menggunakan Teknik Capability Process", Jurnal Ilmiah Teknik Industri, 14 (2), 105 - 112.

Montgomery, D. C. 2013. Statistical Quality Control: A Modern Introduction $7^{\text {th }} E d$. Singapore: John Wiley\&Sons.

Nihan, Kabaday \& Sundus, Dag. 2015. "Process Performance Analysis in the Production Process of Medical Bottles", The International Journal of Business \& Management, 3 (9), $159-167$.

Wooluru, Yerriswamy, et. al. 2014. "The Process Capability Analysis A Tool for Process Performance Measure and Metrics A Case Study", The International Journal for Quality Research, 8 (3), $399-416$. 